\title{
A CIDADE MODERNA: HISTÓRIA, MEMÓRIA E LITERATURA - PARIS, BELO- HORIZONTE
}

\section{A MODERN CITY: HISTORY, MEMORY, AND LITERATURE - PARIS, BELO-HORIZONTE}

\author{
Marcia Senra
}

RESUMO: Este artigo faz uma análise descritiva das características da cidade moderna, a partir de textos que a interpretam-na sob a ótica da literatura. São textos que trazem em comum o discurso de um determinado tempo histórico e que falam da representação da cidade moderna que emergia naquele momento. $A$ abordagem do tema, realizada pela interface entre história, memória e literatura, apresenta a cidade como um discurso, discurso este que é uma linguagem. Por meio de uma linguagem poética, metaforizada, mediada pela vivência, pela paixão e pelo desejo de escritores/ leitores que percorreram as ruas das cidades de Paris e de Belo-Horizonte, símbolos da cidade moderna, pode-se entrever a cultura da modernidade. Cultura que é eminentemente urbana e marcada pelas imagens da constante transformação, fugacidade, artificialidade, inautenticidade, contrastes e fragmentação, enfim, imagens ambivalentes.

Palavras-chave: cidade moderna; modernidade; história; memória; literatura.

ABSTRACT: This article descriptively analyzes the characteristics of a modern city from the perspective of texts that interpret from the literary viewpoint. These texts have in common the discourse of a determined historical point and discuss representations of the modern city, which were beginning at that moment. The theme is treated as an interface between memory, history, and literature, in which the city is presented as a discourse, understood as a language. Through poetic language, metaphorically used, intermediated by the life history, passion, and desire of these writers, who walked through the streets of Paris and Belo-Horizonte, symbols of modern cities, it is possible to glimpse modern culture. This eminent urban culture is marked by images, which are the in constant transformation, fleeting, artificial, non-authentic, contrasting, and fragmented, and thus, ambivalent images.

Keywords: modern city; modernity; history; memory; literature.

\footnotetext{
1 Professora no curso de Direito da Faculdade Cenecista de Varginha (CNEC/FACECA). Doutoranda em Ciências Sociais pela PUC Minas (Belo-Horizonte), bolsa sanduíche na Universidade Nova de Lisboa (Portugal). Email: marcia_senra@oi.com.br.
} 


\section{INTRODUÇÃO}

A proposta deste artigo é uma análise descritiva das características da cidade moderna a partir de textos que a interpretam-na sob a ótica da literatura. São textos que trazem em comum o discurso de um determinado tempo histórico e que falam da representação da cidade moderna que emergia naquele momento. A abordagem do tema, realizada pela interface entre história, memória e literatura, apresenta a cidade como um discurso. Discurso este que é uma linguagem poética, metaforizada, mediada pela vivência, pela paixão e pelo desejo de cada escritor/ leitor que percorre suas ruas.

A fim de se verificar como a linguagem literária é capaz, por intermédio das metáforas e alegorias, construir representações do urbano, neste texto referenciar-se-á a duas cidades a título de casos concretos - Paris e Belo-Horizonte. Para cada uma dessas cidades, dois escritores foram selecionados. Charles Baudelaire e Émile Zola, para Paris e, Carlos Drummond de Andrade e Cyro dos Anjos, para Belo-Horizonte. Dessa maneira, o que norteou o critério da escolha, tanto das cidades quanto dos autores aqui elencados, é o pressuposto de que, como um sistema de ideias e de imagens de representação coletiva, o imaginário é capaz de criar o real do espaço urbano e de seus atores. Mais especificamente, a escolha de Paris centra-se no fato de ter se tornado o paradigma da cidade moderna e, de BeloHorizonte, por ter sido a primeira cidade planejada do Brasil republicano, obra simbólica de maior envergadura da República mineira.

Muitos são os critérios para se tratar a cidade. Critérios como os que apontam para aspectos de ordem topográfica, demográfica, política ou econômica. Ou ainda, a cidade também pode ser vista como um conjunto de signos no qual se inscrevem as manifestações da razão humana. $\mathrm{O}$ que importa é que tudo que é humano é poliocular e plural (SENRA, 2002). A cidade, então, pode ser percebida como ambiente social e histórico construído, fruto da imaginação e do trabalho coletivo do homem que desafia a natureza (ibidem). Nesse contexto, entende-se a cidade como o lugar onde se inscreve a história do urbano e preserva a memória do seu repertório coletivo. Essa história, porém, não é uma simples coleta de referências factuais, mas uma recepção e percepção de lembranças e repertórios perdidos que incidem sobre o espaço da cidade. Conjunto múltiplo de ação coletiva a cidade tem muitas dimensões e significados - reais e virtuais, concretos e simbólicos e, também ela, a cidade, é construtora de identidades e identificações.

Dentro dos limites da cidade, diferentes vetores de espaço e tempo convivem nem sempre de maneira harmônica, ou seja, o cotidiano urbano é plural, polissêmico, singular e diverso. Nesse sentido, a cidade é formada por "[...] múltiplos, variados e heterogêneos conjuntos de atores sociais cuja vida cotidiana transcorre na paisagem urbana [...]" (MAGNANI, 2002, p. 17). Dessa forma, a cidade se torna objeto de múltiplos olhares e discursos que se imbricam sem, necessariamente, serem uns mais importantes ou verdadeiros que outros.

A cidade é, também, um registro e uma escrita. O seu texto é o relato sensível das formas de se ver a cidade, não como mera descrição física, mas, como cidade 
simbólica, que cruza lugar e metáfora. Alegorias, metáforas visuais, explícitas e ou implícitas, expressas nas imagens urbanas e decodificadas apenas por aqueles que dominam o seu código e, também por práticas metafóricas, públicas e privadas, realizadas no território urbano (PESAVENTO, 2002). Assim, o espaço da cidade, como um registro escrito, tem por função dar significado ao tempo e à história e sua materialidade imagética, torna-se um dos suportes da memória social da cidade. A memória urbana trazida pelas imagens e mantida pelos arquétipos fundamentais presentes em todas as sociedades, precisa, portanto, do 'trabalho de 'recordação', sustentado pela escrita, [...] reforçado pela 'rememoração', que inclui elementos ritualísticos, culturais e mitológicos" (BOLLE, 2000 , p. 322; grifo do autor).

E o texto da cidade, nos itinerários urbanos cotidianos, deixa trabalhar a memória e a imaginação, pois, afinal, a cidade não se funda, mas se forma. $E$ Marsílio Ficino dizia que a cidade não é feita de pedras e, sim, por homens; pensamento esse completado por Argan, ao afirmar que são os homens, todos os homens, que atribuem valor a essas pedras (ARGAN, 1991). Nessa perspectiva, se depreende que da pedra com sua dureza se faz o muro, a muralha, a rua, a catedral, o monumento, entretanto, para que haja a cidade, é preciso mais do que the dar um nome. É preciso construir-lhe uma história, revelar suas leituras, eternizar uma memória. "Aí está pois a fórmula da bruxa para transformar 'cidade de pedra' em pedras da cidade: inventar a cidade. [...] Dar-lhe um sentido, traçar-Ihe um destino" (PECHMAN, [199-], s.p). Trata-se de dar a essas formas físicas uma tessitura discursiva, de maneira tal, que a dureza da pedra não se reconheça mais na alma mineral, mas somente na fluidez do discurso. Então, o discurso em seu poder de evocar símbolos, faz da pedra, cidade (ibidem).

Para Benjamin, há duas formas de memória: o monumento e o documento. O monumento, feito para durar e significar, faz parte da memória oficial celebrativa, enquanto o documento, malgrado ele mesmo, aos pedaços, somos nós que ao construirmos o passado, atribuímos sentidos a ele, escrevendo a história (BENJAMIN ${ }^{1}$, [?] apud MATTOS, 1992). Portanto, se a dureza da pedra é a materialidade e a concretude, no entanto, é no registro de seu documento que se inventa a cidade.

\section{AS CIDADES MODERNAS - DA PEDRA AO ESPÍRITO DA CIDADE}

As grandes cidades são a novidade do século XIX. Não pelo tamanho ou pelos progressos arquitetônicos, mas, sim, por um fenômeno absolutamente novo - o fenômeno urbano. A multidão nas ruas, o flâneur, a concentração da população em um mesmo espaço, a moradia precária, o apito da fábrica a marcar e disciplinar o ritmo dessa multidão, orientando 0 cotidiano dos indivíduos nas grandes cidades. Nesse aspecto, a cidade passara a representar a própria civilização à medida que a vida urbana é vista como um destino inexorável. A cidade deixa de ser um lugar de abrigo, proteção e refúgio, escapulindo à sua condição mineral e se torna um aparato comunicacional do entrecruzamento dos discursos do processo civilizatório. Assim, a

\footnotetext{
${ }^{1} \mathrm{O}$ texto consultado não apresenta a referência do autor
} mencionado. 
cidade é o laboratório onde a civilização moderna, portadora dos ideais do progresso e da crença no poder das ciências, está sendo gestada. Durante todo o século XIX e início do XX, diferentes olhares se voltaram para a cidade, com o intuito de identificar e desvendar, ali, o novo enigma a ser decifrado.

Um desses olhares é pela perspectiva da literatura, em cujas representações do urbano qualificaram o social, "identificando uma reconstrução do mundo sensível que se expressou em discursos e também em imagens - visuais e mentais - evocadas pelo texto literário" (PESAVENTO, 2002, p. 14). Nas páginas da literatura, vão se construindo as identidades sociais $e$ a constituição do imaginário sobre as cidades modernas.

As cidades, como espaços de vivências coletivas, são paisagens privilegiadas de registros da memória. A pena dos escritores faz dessas paisagens vivas narrativas, que na interseção com a história, expressam, de forma policromática, a vida das pessoas no cotidiano [...] (DELGADO, 2006, p. 117 apud DELGADO, 2007, p. 152).

Portanto, conforme Delgado (2007), não raras vezes, as memórias e metáforas tecem, na literatura, representações individuais e coletivas sobre a vida urbana. As representações literárias do urbano revelam um retrato em movimento de uma determinada conjuntura histórica que, de forma narrativa, expressam as sensibilidades e as percepções das mudanças em curso, em uma apresentação da realidade da vida social (DELGADO, 2007; PESAVENTO, 2002). Palavras e imagens, interseção entre literatura, história e memória - amálgama entre realidade e ficção. O que comumente se chama de realidade é algo extremamente caótico e em constante fluxo. Pressupõe-se, então, que toda representação se refere ao real, mas não simplesmente o espelha, mas, sim, o reconstrói de uma outra maneira (ANDRADE, 1996). Assim, nas representações da cidade, tratada como ideia ou imagem e nem sempre conformadas numa visão unívoca, há, entretanto, certos aspectos que devem ser destacados. As imagens mais recorrentes e reveladoras da essência da cidade moderna e do homem moderno são:

a imagem da cidade como lugar da artificialidade e da inautenticidade; das transformações e da perda das referências físicas, sociais e afetivas; da homogeneidade mas também da diversidade e da heterogeneidade; dos contrastes; da percepção fragmentada, fugaz e subjetiva, e das instituições culturais e artísticas (ANDRADE, 1996, p. 33-4).

Tomando, então, por referência as análises realizadas pela autora supramencionada, em relação às representações da cidade moderna, abordam-se, a seguir, os elementos constitutivos dessas imagens.

A intervenção planejada do homem na organização do espaço urbano, é uma das principais fontes da imagem da cidade como reino do artifício e do inautêntico. Isso porque, acreditava-se que a relação entre o homem e a natureza deveria ser pautada pela harmonia, vez que, o homem para sobreviver, não precisaria intervir e alterar a 
natureza. Com relação ao citadino, a artificialidade é, muitas vezes, representada pelo ser mecanizado, autômato que se assemelha às máquinas, dominado por gestos mecânicos e repetitivos, comandado pelo tempo artificial do relógio. Já, a inautenticidade da vida urbana advém de suas tirânicas convenções sociais ou do poder do dinheiro, que produzem pessoas falsas, mascaradas, sem virtudes e corruptas. Contudo, há, também, o anonimato, expresso no fascínio estético pela multidão.

No século XIX, o crescimento das grandes cidades surpreendeu os homens pelas constantes transformações e consequente destruição dos marcos da tradição e do passado, apagando rastros, alterando tanto as relações de trabalho quanto a paisagem das ruas e, até mesmo, a rotina doméstica. Dessa maneira, "o habitante das cidades teve que conviver com o desenraizamento e a destruição e perda constantes das referências físicas, sociais e afetivas" (ibidem, p. 39). Na cidade da modernidade, locus do efêmero, transitório e contingente, a literatura explorou os temas do desamparo, da alienação e do exílio em seu próprio país ou cidade.

Os aspectos físicos da cidade moderna, por meio de símbolos, imagens e sentimentos que povoaram a imaginação dos escritores deram origem à visão de homogeneidade e ou de heterogeneidade. $A$ vastidão de seus espaços, o labirinto de suas ruas e construções que se repetem, marca o lugar da uniformidade, do homogêneo e do geometrizante, facilmente mapeável para quem planeja a cidade. Mas também a cidade é o espaço da diversidade e heterogeneidade de raças, profissões, valores, nacionalidades e experiências (ibidem), pois, com efeito, ela é o lugar das massas e da multidão indiferenciadas. Os contrastes, consequência da grande diversidade, na cidade moderna, são expressos, sobretudo, pelos seguintes elementos contrastivos: pobreza e riqueza, degradação e opulência, ordem e caos, liberdade e controle, barbárie e civilização, sedução e temor pelo radicalmente novo, trabalho e ócio, intelectualidade e futilidade, solidão e multidão, processos individualizantes e massificantes, a cidade diurna e a cidade noturna, cada qual com seus personagens e ordens distintas (ibidem).

A extrema complexidade da vida e a diferenciação social e espacial, geradas pela divisão do trabalho, implicaram na mudança da percepção da cidade, que passou a se dar de forma essencialmente fragmentada, sobre a qual as imagens retratam partes ou aspectos da cidade. Abriu-se mão de se abarcar a cidade em sua totalidade, uma vez que ela perdeu sua unidade e seus limites geográficos e literários também, porque esse passou a expressar fragmentos do tempo real (ibidem). Por outro lado, as cidades sempre atraíram os escritores, pois nelas se encontravam as instituições literárias básicas que proporcionavam condições para o fomento e a produção de bens culturais, portanto, fortalecendo a imagem da cidade como centro de cultura (ibidem). Consequentemente, de forma ambivalente, a experiência com a grande cidade exigiu da literatura uma nova maneira de representar o homem e seu meio, a fim de que pudesse captar a vida cada vez mais caótica, fragmentada e fluida no espaço urbano. Era preciso, para mostrar a 
fisionomia da grande cidade, dar conta de suas facetas múltiplas e condensar, num instantâneo, a sua complexa simultaneidade (BOLLE, 2000).

No ensaio " $A$ cidade segundo $O$ pensamento europeu - de Voltaire a Spengler", de 1989, Carl Schorske aponta que, a partir do século XVIII as cidades são definidas segundo três conceitos: a cidade como virtude; a cidade como vício; e a cidade além do bem e do mal. A cada uma delas correspondeu um determinado contexto histórico, porém elas sobreviveram uma às outras, muito embora sua vitalidade tenha sido minada e seu brilho ofuscado pela sucedânea. A filosofia iluminista, no século XVIII, desenvolveu o conceito de cidade como uma civilizada virtude, abrindo caminho para 0 progresso cultural e industrial, enquanto o século XIX, no encalço da industrialização, trouxe a visão antagônica: a cidade como vício. "A cidade simbolizava, em tijolos, sujeira e miséria, o crime social da época" (SCHORSKE, 1989, p. 51). Nessa perspectiva, a cidade, como símbolo estigmatizado desses vícios sociais, fora apanhada pela fina rede psicológica de esperanças perdidas.

O terceiro conceito, resultado de uma cultura subjetivista e de uma atitude intelectual de contestação explícita, a validade da moral tradicional, do pensamento social e da arte no final do século XIX, colocou a cidade entre o bem e o mal. "A prioridade da razão humana, a estrutura racional da natureza e a significação da história foram colocadas frente ao tribunal psicológico individual”, o que "inevitavelmente tirou a cidade de seu trilho" (ibidem, p. 54). Dessa forma, os intelectuais que redefiniram os valores do que é o moderno deram um novo rumo à questão e entre as verdades encontradas estava a cidade,

com todas as suas glórias e horrores, suas belezas e feiúras, como motivo essencial da existência moderna. Não quiseram julgá-la eticamente: experimentá-la completamente tornou-se o objetivo deste novi homines da cultura moderna. [...] Para a nova cultura, a cidade não tinha uma estrutura temporal localizada entre passado e futuro, mas exatamente uma qualidade temporal. A cidade moderna oferecia um eterno hic et nunc, cujo conteúdo era passageiro, mas cuja transição era permanente. A cidade apresentava uma sucessão de momentos variados e passageiros [...]. Para este modo de pensamento a experiência da multidão era básica: todos os indivíduos desarraigados, todos únicos [...] (ibidem, p. 54).

Assim, as transformações, na apreensão e nas representações da cidade em constante movimento, trouxeram à baila os sentimentos de atração e repulsa, dissociação, descontinuidade temporal, fragmentação, contrastes, transitoriedade e anonimato, respostas ambivalentes alimentadas pela condição de um mundo em transição e pelas próprias forças díspares e conflituosas da vida moderna.

\section{DE PARIS PARA O MUNDO - SÍMBOLO DA MODERNIDADE}

Neste contexto, Paris constitui-se no paradigma da cidade moderna ou na sua 
metonímia - é a capital do século XIX. Ou seja, a simples evocação mágica de seu nome traz à lembrança todo o processo mais amplo que comporta e configura a grande cidade, isto é, torna-se uma parte para expressar o todo (PESAVENTO, 2002). Paris tem sido a cidade mais representada, em texto, prosa e imagem, estimulando todo um imaginário social. E, segundo Pesavento (ibidem), por força da prática do imaginário social e da sensibilidade coletiva, historicamente vivenciada e transmitida no cotidiano daqueles que habitam uma grande cidade ou desejariam vivenciá-la, essas representações não são sentidas como imaginários, mas sim, como uma realidade de força indiscutível. $\mathrm{Na}$ concepção de cidade além do bem e do mal, é que se insere a construção mítica de Paris, metrópole constituída por um imaginário social vindo da experiência histórica coletiva e individual da modernidade.

Ora, dessa forma, é na Paris do século XIX, mítica e fantasmagórica, que as antinomias urbanas se revelam no entrechoque de formas arcaicas e novas e no entrecruzamento dos valores do progresso e da tradição, nas representações polissêmicas e polifônicas da modernidade. É a Paris haussmaniana de Charles Baudelaire e de Émile Zola, cujo alcance das intervenções foi tão grande que o fenômeno ganhou o mundo - de Paris para o mundo, como modelo acabado da metrópole do século XIX. Numa tentativa de racionalização do espaço, a haussmanização de Paris foi, antes de tudo, uma resposta às demandas múltiplas que agitavam a cidade desde o início do século XIX: crescimento demográfico, pressão econômica, especulação do mercado imobiliário, medo social, doenças e a revolta.
A reforma haussmaniana da capital francesa se norteou pelos princípios da cidade aberta, apregoados desde o século XVIII, presentes no pensamento e discussões dos higienistas, engenheiros e técnicos da cidade com seu horror às aglomerações. "A teoria dos miasmas - que indicava que o ar estava contaminado pelas emanações mefíticas oriundas da cidade era responsável pelas epidemias [...]" (PECHMAN, 1994, p. 5). Em contraponto a essa perspectiva, o corpus básico sustentou-se "no princípio de que tudo que era movimento e circulação era são e tudo o que estagna é malsão" (PESAVENTO, 2002, p. 93). Assim, a visão médica da cidadecorpo como doença daria o fundamento para as reformas urbanas ocorridas em Paris no século XIX, mas também, se alastraria por outros países, inclusive o Brasil.

Por tudo abaixo, demolir, revirar a cidade, (re)construir, valorizar o solo urbano, desenvolver os meios de comunicação e otimizar a prestação de serviços públicos configuram-se como oportunidades ímpares de investimento de capitais. Então, aos imperativos da estética, higiene e da técnica alia-se a ideia do lucro. "A cidade é, portanto, o ponto de convergência de uma multiplicidade de olhares que irão fundamentar a constituição de uma nova forma de dominação apoiada no conhecimento científico, na intervenção espacial e na disciplinarização de mentes e corpos" (PECHMAN, 1994, p. 6). Todavia, tais reformas urbanas não corresponderam às necessidades das camadas sociais subalternas, muito embora o discurso tenha sido realizado em nome do interesse do povo. O resultado das intervenções urbanas em Paris foi a alteração de sua paisagem, mudando seu visual. Os principais 
destaques a se elencar, nessa nova paisagem urbana, vinculam-se à anexação e integração da banlieue, aumentando a superfície e a população da cidade, a mudança forçada da população mais pobre para a periferia, ao predomínio da linha reta porque esta procura abolir o acaso, e do princípio axial e das largas avenidas, inclusive com a construção das doze avenidas irradiadas a partir da Place de l'Étoile, a uniformidade das fachadas, calçadas largas e o espetáculo das ruas (PESAVENTO, 2002). Tudo se passava como em um desfile.

Dificilmente a flânerie poderia ter se desenvolvido em toda plenitude sem as galerias - "caminhos cobertos de vidro e revestidos de mármore, [...] de ambos os lados dessas vias se estendiam os mais elegantes estabelecimentos comerciais, de modo que uma de tais passagens é como uma cidade, um mundo em miniatura" (BENJAMIN, 1991, p. 35). As relações entre os indivíduos na cidade moderna se distinguem por sua notória preponderância da atividade visual sobre a auditiva. Como afirma Pesavento (2002), Haussmann, ao deixar marcas visíveis no traçado urbano, fixou uma imagem visual de cidade moderna e acabou por consolidar o mito de Paris como a metrópole, por excelência, do século $\mathrm{XIX}$.

Para Schorske (1989), aquilo que se chama de espaço visual da cidade, o sentimento espacial da cidade, é feito por relações associativas e se constitui naquele tesouro interior que é o espírito da cidade, o qual permite nos identificarmos como seus cidadãos, do mesmo modo que uma língua nos identifica como pertencentes a um determinado lugar. Nesse contexto, o espaço visual da cidade configura, de forma axiológica, pontos de referência afetivos ou habituais, com seu complicado, rico e significativo conjunto de signos e sinais, ritos e mitos, formando uma rede de imagens mnemônicas capazes de referendar e dar o sentido de pertença para seus habitantes. "Identidades referem-se a atributos culturais, simbologias, experiências, hábitos, crenças, valores. Remete a um elenco de variáveis em permanente construção" (DELGADO, 2006, p.47), e o trabalho da memória é de vital importância para o reconhecimento desses laços de identidade, já que contribui para a internalização de significados e experiências. A Paris imaginária que se constrói contra e a favor da Paris real é responsabilidade daqueles espectadores privilegiados do social que, sob sua égide, resgatam a sintonia fina de uma época, traduzindo-a em versos, textos e imagens literárias (PESAVENTO, 2002). "Assim é que a Paris de Haussmann será 'lida' por Baudelaire e por Zola, em especial" (ibidem, p. 99).

Charles Baudelaire nasceu no primeiro quartel do século XIX e morreu em 1867. O poeta "inaugura aquilo que Schorske chama de cultura de subjetividade aplicada ao urbano, e que se constituiria numa dimensão universal para o entendimento da metrópole moderna" (ibidem, p.100). Precursor do simbolismo e, para muitos, criador da expressão modernidade, soube esculpir com palavras e transformar em versos a Paris do canteiro de obras, num contínuo de transformações. Baudelaire fala das fábricas em atividade, das chaminés, dos campanários, do herói moderno obrigado a conviver com a transitoriedade permanente e da presença da multidão. Junto à experiência da multidão, da massa de 
indivíduos, na qual o indivíduo se refugia, caminha o sentimento da solidão. Com efeito, esse sentimento do contraste com as grandes massas citadinas - essa multidão amorfa dos transeuntes na rua pode ser observada num pequeno fragmento do poema "Um Dia de Chuva", escrito por Baudelaire, em meados do dezenove: "Cada um, nos acotovelando sobre a calçada escorregadia. Egoísta e brutal, passa e nos enlameia, ou, para correr mais rápido, distanciando-se nos empurra. [...]" (BAUDELAIRE, 1929 apud BENJAMIN, 1991).

Assim, a experiência de Baudelaire com a multidão comportava os rastros da iniquidade e dos milhares de encontrões que sofre o transeunte ao passar por aquela massa que não constitui nenhuma classe, nenhum coletivo articulado e estruturado. A cidade de Baudelaire é a cidade aberta, virtude e vício, para além do bem e do mal, palco da vida humana e lugar onde as coisas acontecem.

Tudo em Paris está fervilhando num verdadeiro formigueiro de paixões mundanas, a vida flui intensamente e todo mundo quer participar deste universo dionisíaco de prazeres. Baudelaire está neste meio, vestido à moda 'dandy' de sobrecasaca e gravata, ele fuma sossegadamente - seu cachimbo num canto qualquer de uma destas casas noturnas e observa atento esse ritmo contagioso... Num outro canto da velha Paris, existe paralelamente os guetos e o submundo da prostituição. Mulheres de vida fácil vendem 0 corpo em orgias desenfreadas, satisfazendo assim à todas as taras dos mais afortunados. [...] Paris parece mesmo um sonho repleto de luxúria e longe de ser somente ilusão. A cidade vive intensamente o ritmo da modernidade. Existem duas Paris, uma sonho e ilusão, outra de podridão e miséria. [E] Baudelaire saberá interpretar este contraste social... (ALMEIDA, [2008], s.p).

Como um citadino da Paris de Haussmann, Baudelaire, em sua obra, resgata os inevitáveis contrastes presentes na cidade grande. A crítica social emerge entre os extremos de luxo e os da pobreza, do belo e do feio, dandismo e compaixão popular, sonho e despertar. Por um lado, a imagem dos duplos percorre a prosa e a poesia de Baudelaire numa apreciação das disfunções da cidade, que geram sentimentos contraditórios e superpõem todas as situações possíveis (PESAVENTO, 2002). Mas, por outro lado, a ambivalência e o recurso às imagens contrastivas são decorrentes também da própria posição do autor diante da cidade que tanto amava e, ao mesmo tempo, era capaz de desprezar pela sua vulgaridade (ibidem). Exilado nessa cidade de tantas transformações, Baudelaire se debate entre a perda de referências e a sensação de pertencimento a essa metrópole onde vive e à sua incapacidade de mudar com ela, Ihe dando um sentimento de estrangeirismo no próprio território.

Já o texto literário de Zola, numa junção de sua sensibilidade reveladora do imaginário social do viver metropolitano com as mudanças pelas quais a capital da França passava, é um libelo do seu amor pela cidade e do dizer a cidade durante e pós-Haussmann (ibidem). Émile Édouard 
Charles Antoine Zola nasceu em 1840 e faleceu em 1902. Zola foi responsável por conceber a teoria do romance experimental, na qual se pretende que o escritor assuma o papel de experimentador que pesquisa a relação entre o comportamento individual, condicionado pelos caracteres hereditários transmitidos $e$ as transformações que ocorrem, naquele indivíduo, em função do ambiente social no qual se insere.

Por meio de sua obra cíclica, escrita entre os anos de 1871 e 1893, e composta por vinte volumes, na qual narra a saga de uma família que se ramifica em todas as classes sociais, "Os Rougon-Macquart, História Natural e Social de uma Família sob o Segundo Império", Zola materializa sua tese do romance experimental. Nessa obra, o autor retrata, de forma detalhada, todos os aspectos da sociedade francesa durante o segundo império; período que se estende de 1852 a 1870. A haussmanização de Paris perpassa a obra de Zola de maneira a apontar que "assim esquartejada, estripada, dilacerada, a cidade se abria a toda sorte de negociatas, falsificações e expropriações, proporcionando uma alta lucratividade para os especuladores e suas operações fraudulentas [...]", segundo Pesavento (2002, p. 116). Contudo, se há uma condenação moral dessa exploração desmedida e talvez uma vaga melancolia concernente ante a velha Paris posta abaixo, o sentimento de estrangeiridade diante da cidade, entretanto, não leva Zola a lamentar, verdadeiramente, a sua transformação (ibidem). "[...] É a nova Paris que se destaca na narrativa de Zola, com suas novas formas arquiteturais, seu novo traçado urbano e seus também novos espaços de lazer" (ibidem, p. 118-9). Nos dois excertos a seguir, ficam evidenciadas essas abordagens nas obras de Zola:

'Aristides Saccard, desde os primeiros dias, sentia a chegada desta onda crescente de especulações, da qual a espuma ia cobrir Paris inteira. Ele seguiu estes progressos com uma atenção profunda. Ele se encontrava bem no meio desta chuva quente de dinheiro tombando direto sobre os tetos da cidade. Nas suas andanças contínuas [...], ele tinha surpreendido o vasto projeto de transformação de Paris [...] deste ágil formidável [...], pela batalha dos interesses e o fulguramento do luxo desmedido' (ZOLA, 1984, p. 39 apud PESAVENTO, 2002, p. 115).

'Revolucionou-se o quarteirão [...]. Abria-se o boulevar Magenta e o boulevard Ornano [...]. Era de não mais se reconhecer. [...] Agora, da Rua de La Goutte d'Or se via uma imensa clareira, um raio de sol e de ar livre; e, no lugar dos cortiços que impediam a vista deste lado, se erguia, sobre o boulevard Ornano, um verdadeiro monumento, uma casa de seis andares, esculpida como uma igreja, da qual as janelas claras, ornadas de cortinas bordadas, transcendiam a riqueza' (ZOLA, 1983, p. 427 apud PESAVENTO, 2002, p. 118).

Paris aberta, ostentando os contrastes na cidade que se renova - áreas de pobreza e de riqueza, que evidenciam, na distribuição do espaço, a desigualdade social. Cidade devorada, posta aos pedaços, mas que, acima de tudo, era movimento e circulação numa atividade febril que não 
deixava de impactar. Era, concomitantemente, um éden e um inferno social.

'Mas, acima de tudo, o que ensurdecia as pessoas não era a trepidação das máquinas; tudo marchava a vapor, os assobios agudos rasgavam o ar; enquanto que, ao mesmo golpe de vento, uma nuvem de gesso se erguia $e$ se abatia sobre tetos circunvizinhos, como se fosse neve a cair. [...] as equipes se sucediam, os martelos não paravam, as máquinas silvavam continuamente [...]' (ZOLA, [1883?], p. 196 apud PESAVENTO, 2002, p. 117).

Numa verdadeira "cartografia literária", traduzindo uma visão crítica do urbano, Zola descreve ruas, prédios, interiores, quarteirões e panoramas - lugares da cidade, com precisão de detalhes, construindo seu espaço imaginário no sentido de dar efeito de real à sua narrativa (PESAVENTO, 2002). Portanto, assim como em Baudelaire, na obra de Zola encontrarse-ão presentes os traços que arrogaram o corpus da visão literária sobre a cidade moderna: o recurso da linguagem metafórica e alegórica; a cidade aberta, metrópole plena de contrastes; a imagem da multidão; a questão social urbana; a ambivalência retórica e a compreensão do escritor como um voyer, transeunte e leitor privilegiado do urbano. Com seus vícios e torpezas, seduções e encantamentos que se impõem e ultrapassam a dimensão polarizada da cidade vício e da cidade virtude, o ethos urbano confere uma identidade à cidade muito além do bem e do mal. Assim, a construção de um olhar literário sobre a cidade de Paris tornou-a um paradigma da modernidade urbana. Ao mesmo tempo, essa Paris-capital-do-mundo é, conforme Bancquart (1997, p. 15 apud PESAVENTO, 2002 , p. 139) que "[...] se torna um personagem, uma cidade-texto, que liga a seu espaço e à sua história toda uma rede de referências poéticas, míticas, pessoais. É uma cidade do desejo, que possui um imaginário intenso.

Paris se diverte. Paris! E só esta palavra diz, não sei que estranhos mundos de sonho, de volúpia, de enternecimento. $E$ há milhões de almas sonhando Paris, endeusando-a, desejando-a com amor, com frenesi como se deseja uma mulher amada que vive em outro continente. $E$ todos os povos do mundo têm a idéia de que Paris é a grande cocote, a licenciosa barregã, de espírito vivo e azougado champanhe com quem se passa noites de folia e os dias de prazer [...] (SAMPAIO, 1909 apud ALMEIDA, [2008], s.p).

Esse encantamento por Paris e por seu modelo de metrópole moderna, universalmente consensual, reverberá no Brasil, inclusive com efeitos sobre a nova capital mineira. Paris, fonte inspiradora de um imaginário exportável refletirá a imagem sobre a qual Belo Horizonte debruçar-se-á.

\section{BELO-HORIZONTE - DAS MINAS E DAS GERAES}

A capital mineira, Belo-Horizonte, diferentemente de Paris que existe há milhares de anos, conta com pouco mais de um século de existência. Construída no final 
do século XIX, sob o signo da modernidade urbanística, foi oficialmente inaugurada no dia 12 de dezembro de 1897. Porém suas obras se estenderam até meados da década de 1910. Nascida com o destino estabelecido para ser a nova capital administrativa do estado de Minas Gerais, em substituição à antiga - a cidade de Ouro Preto, e sob os auspícios da República recém implantada no país, Belo-Horizonte representava a possibilidade de rompimento com a tradição colonial. Afinal, não só se edificava uma capital, como também se procurava construir uma República brasileira, ambas, expressões de um partilhamento de um código comum: um desejo de renovação da sociedade. Viver a desenvoltura da modernidade e romper os laços de uma sociedade que, até então, permanecera encerrada em moldes tradicionais. Portanto, o novo tempo pressupunha uma nova espacialidade capaz de orientar um sentido material e simbólico à ideia de ruptura.

Ao mesmo tempo em que o alto grau de abstração e de rigor geométrico da planta da cidade professava a utopia de se traçar, com régua e compasso, uma ordem social harmônica, unitária, na qual não haveria lugar para a chamada desordem urbana, a um só golpe justapunha-se a realidade a um modelo de cidade. Isto porque o imprevisível e a atuação conflitante dos atores urbanos seriam inibidos por uma gestão técnicoracional do espaço. O pequeno povoado do Curral d'El Rei foi completamente demolido para, em seu lugar, se erguer aquela que representaria o signo de um novo tempo, centro de desenvolvimento intelectual e de novas formas de riqueza e trabalho, foco irradiador da civilização e progresso, lugar moderno, higiênico, elegante, capaz de consolidar a aventura da modernidade Belo-Horizonte (JULIÃO, 1996).

Então, para se construir a nova capital, significava, praticamente, copiar um repertório urbanístico em voga no mundo e que se difundira para os países periféricos, sobretudo, em forma de clichês. Nesse contexto, a Comissão Construtora da Capital foi fiel aos mandamentos urbanísticos já consagrados na Europa, principalmente, o modelo da Paris de Haussmann. A planta geral da cidade apresentada ao governo de Minas, em 1895, confirmava a incorporação do corpus básico dos princípios norteadores da cidade aberta: os espaços abertos e iluminados de uma geometria clara e arejada, para a higiene coletiva, colocavam todos sob as vistas de todos, cerceando proximidades e contágios promíscuos entre os homens e entre esses e os elementos ambientais suspeitos (ibidem).

A [...] supremacia no traçado de Belo-Horizonte assinalava um ajuste às novas demandas da vida moderna. Era um indício de um padrão de sociabilidade, voltado para o espaço público, cosmopolita e urbano. Também as ruas e avenidas, com suas dimensões monumentais, constituíam verdadeiras artérias, apropriadas ao tráfego, à circulação de mercadorias, da multidão e dos veículos - lugares de trânsito e negócios. A construção do espaço projetava uma imagem da cidade associada à do movimento frenético e desimpedido de coisas e pessoas (ibidem, p. 58).

Outrossim, da mesma forma que as reformas haussmanianas em Paris, 
alojaram, na periferia, as populações mais pobres, em Belo-Horizonte o próprio projeto da capital, ao separar a zona urbana da suburbana por uma avenida de contorno, a atual Avenida do Contorno, exprimiu uma lógica segregacionista que logrou perpetuar, no espaço urbano, as fronteiras entre ricos e pobres. $\mathrm{Na}$ área central localizada na zona urbana, destinada aos edifícios públicos, com espaços coletivos mais atraentes e com serviços urbanos modernos, foi o local onde a população mais abastada construiu sua residência. Aos pobres coube a zona suburbana que veio a se transformar na primeira vastas periferias da capital e, ainda, a área rural no entorno da anterior. Dessa maneira, a compartimentação da cidade estabelecia barreiras invisíveis entre os diversos segmentos sociais e homogeneizava os espaços.

Nesse sentido, Belo-Horizonte assemelhava-se, espacialmente, a cidades de países desenvolvidos, entretanto, estava longe de engendrar uma modernidade que, de fato, atingisse e transformasse profundamente as estruturas da sociedade. A modernidade, na nova capital mineira, assumiu muito mais seus aspectos normativos e excludentes que suas promessas emancipatórias, uma vez que seu espaço planejado destinou-se à ínfima parcela da sociedade - as elites burocratoadministrativas, principalmente. "A capital não passava de um cenário fundado na miragem do progresso, monumento de uma sociedade empenhada numa modernização superficial [...]" (ibidem, p. 62). Assim, não é surpresa o comentário de Monteiro Lobato no tocante ao aspecto artificial e pouco humano da capital, quando de sua primeira visita: "Existe uma escassez de gente pelas ruas larguíssimas, a cidade semi-construída, quase que apenas desenhada a tijolo, no chão [...]" (LOBATO, 1947 apud JULIÃO, 1996, p. 62).

Andrade mostra em sua tese, "Representações Ambivalentes da Cidade Moderna: A Belo-Horizonte dos Modernistas" (1996), na qual investiga as representações de Belo-Horizonte, construídas por alguns escritores modernistas dois aspectos mais relevantes nessas representações. O primeiro é a marca da ambivalência decorrente das tensões da passagem da sociedade tradicional para a moderna, inerentes à própria modernidade. A reconstrução memorialística corresponde ao segundo aspecto. Essa reconstrução memorialística contribuiu para a construção do mito de uma Belo-Horizonte culta, humana e acolhedora em contraposição à representação anterior: provinciana, periférica e tradicional. Segundo a autora referida (1996), na literatura modernista belo-horizontina, repleta de referências às suas ruas e habitantes, o que se observa é uma mescla de ficção com relatos de experiências vividas compartilhadas tanto pela autobiografia quanto por certas obras de ficção. E é nessa perspectiva que se enquadram os poemas e crônicas de Drummond e os romances de Cyro dos Anjos.

Carlos Drummond de Andrade nasceu no interior de Minas Gerais, em Itabira, no início do século passado, e morreu no final dos anos de 1980. Funcionário público, morou a maior parte de sua vida na cidade do Rio de Janeiro. Com algumas pequenas interrupções, residiu em Belo-Horizonte, entre os anos de 1916 e 1933. Sua obra, extensa e constante, registra as impressões das cidades que morou e, no caso de Belo- 
Horizonte, suas primeiras produções e poemas e crônicas memorialísticas (ANDRADE, 1996). Belo-Horizonte é para o escritor uma cidade fundamentalmente provinciana, porque não só estava longe do centro e das modas, mas também, porque era conservadora, pequena, parada e com vida social restrita das cidades do interior, tendo, assim, sua representação como tediosa e parada (ibidem). "Perde o amor mais uma parada / nesta Citera provincial. Tarde, fecha-se o Parque. Nada / acontece de bem ou mal" (ANDRADE, 1979 apud ANDRADE, 1996, p. 145). No entanto, de maneira ambivalente, apesar de criticar o provincianismo, o tradicionalismo e a quietude da cidade, Carlos Drumonnd é muito saudosista da vida interiorana onde nada muda (ANDRADE, 1996). Ainda, para Belo-Horizonte, em Drumonnd, são distinguidas duas importantes maneiras de se tratar o moderno: como moda no sentido de algo passageiro e fugaz:

'Nesta seção se falará de moda, de sentimentos que passam com ela, de atrizes bonitas de cinema, de poetas [...], e de mil outros assuntos terrestres. A senha será: Frivolidade [...], A seção será curta, como a vida, mas sem as complicações da vida [...]. A preocupação única é: aborrecer pouco, aborrecer o menos possível' (ANDRADE, 1984 apud ANDRADE, 1996, p. 142).

E, como algo negativo, quando se refere à impessoalidade e banalização da vida moderna e à geometria e à arquitetura da cidade "perfeitamente arborizada, aerada, iluminada [...]", ou, ainda, "Por que ruas tão largas? / Por que ruas tão retas? / [...] / Cidade grande é isso? / [...] / Aqui tudo é exposto / Evidente [...]" (ANDRADE, 1988, apud ANDRADE, 1996, p. 151). $\mathrm{Na}$ impossibilidade de retratar na totalidade a realidade complexa de uma cidade, em função de sua diversidade e complexidade crescentes, a obra de Drumonnd, sobremaneira, explora a região central da capital mineira, inclusive, sem muita ênfase no tocante às diferenças sociais e geográficas (ANDRADE, 1996). Entretanto, a transferência do escritor para a capital federal alterou de modo significativo o sentido de suas representações sobre BeloHorizonte. "Se o que marcou as primeiras crônicas [...] foi a descrição do cotidiano da cidade, a partir de sua mudança este the escapa e o que lhe resta é a memória" (ibidem, p. 157). Como combinar as imagens guardadas com a cidade atual, e como compreender as suas mudanças? A resposta é a crítica ao progresso, à intervenção planejada dos homens no espaço, a reinterpretação da quietude da cidade como algo positivo e o desejo inglório de preservar a cidade, que não existe mais por causa das constantes demolições e construções. Assim, por meio da memória, resistir ao inevitável de todas as cidades modernas: a permanência das transformações (ibidem).

Se antes representou BeloHorizonte como uma cidade homogênea e impessoal, reafirmando seus vínculos com o espaço mais heterogêneo e humano das cidades do interior, depois Belo Horizonte dos anos vinte passou a ocupar na afetividade o lugar e o significado das cidades interioranas e ele se recusou a aceitar a Belo-Horizonte atual (ibidem, p. 160). 
Nesse contexto, a idealização da BeloHorizonte dos anos vinte e o desejo do escritor em eternizá-la e torná-la imutável acabou por criar a imagem mitológica da cidade. A nova capital, surgida em consonância com o projeto republicano, engendrou uma cidade onde a experiência da modernidade se mostrou ambígua e paradoxal na vida indefinida e híbrida, hesitante entre ora o passado, ora o futuro. Para muitos, era apenas um belo cenário, um divino corpo com alma de arraial e que não passava de uma poeirópolis (JULIÃO, 1996). E, "para outros, era o desenvolvimento inédito, uma verdadeira “avançada para o futuro'” (ibidem, p. 52). Belo-Horizonte em função de sua conformação espacial que constrangia a interação social não cumpriu com a vocação precípua de uma cidade, isto é, a cidade como locus de promoção da integração entre os homens que deve proporcionar espaços para a expressão das diferenças. "As praças, ruas, cafés, apesar de convidativos aos encontros, pareciam entregues ao abandono ou eram, então, usufruídos timidamente" (ibidem, p. 64).

Além do mais, como já denunciado por Drummond, na cidade persistiam costumes identificados como provincianos. Mas era necessário banir esses hábitos cultivados na capital mineira, pois o projeto civilizatório impunha um estilo de vida cosmopolita e mundano, tal como o modelo importado da França. "Esse desajuste entre o espaço e a vida social decorria [...] da ausência de identidade entre seus habitantes desenraizados e o urbanismo radicalmente inovador. Daí, as incongruências [...]" (ibidem, p. 67). Vale destacar que "a identidade, além de seus aspectos estritamente individuais, apresenta dimensão coletiva, que se refere à integração do homem como sujeito do processo de construção da História" (DELGADO, 2006, p. 51). Então, como a maioria da população da capital provinha do interior do estado pelo fato da recente construção da cidade, seus habitantes, muito provavelmente, ainda não haviam estabelecido relações associativas que se constituiriam naquele tesouro interior que é - espírito da cidade e que nos permite identificarmos como seus cidadãos. O que não foi o caso de Cyro dos Anjos.

Uma das principais ambivalências das representações de Cyro dos Anjos sobre Belo-Horizonte é o sentimento de exclusão. Cyro Versiani dos Anjos nasceu na cidade de Montes Claros, em 1906, e faleceu no Rio de Janeiro, em 1994. Funcionário público e jornalista morou, além de BeloHorizonte, em Brasília e no Rio de Janeiro. Sua obra mais conhecida é "O Amanuense Belmiro", de 1937, na qual a capital tem lugar privilegiado.

A parte central da cidade e os estratos médios, a maioria envolvida com a burocracia estatal ou com o jornalismo, assim como ele e Drummond, tem, em Anjos, prioridade nas narrativas. Contudo, como homem vindo do interior, é nessa perspectiva que seu olhar vê a cidade. Assim, destaca principalmente as diferenças entre a capital e o interior. Portanto, para o jovem de Montes Claros, Belo-Horizonte pareceu uma cidade monumental, moderna, trepidante e cheia de novidades, mas, paulatinamente, tal qual Drummond, percebe que a moderna cidade abrigava também o espírito conservador, provinciano. Era uma cidade parada, isolada e periférica. Nos dois fragmentos, a seguir, do livro " $O$ 
Amanuense Belmiro", pode-se observar essas representações da cidade de BeloHorizonte:

'Do alto da colina, contemplei BeloHorizonte, que apenas despertava. As cores, já vivas, do céu e a luminosa beleza da cidade feriramme os olhos. Os edifícios suntuosos, os grandes jardins públicos, as retas avenidas situam Belo-Horizonte fora dos quadros habituais de Minas. Dentro das casas mora, porém, o mesmo e venerável espírito de Sabarabuçu, Tejuco, Ouro Preto e de tantas outras vetustas cidades' (ANJOS, 1979 apud ANDRADE, 1996, p. 116).

'Cidade besta, Belo-Horizonte! Exclamou Redelvim, consultando o relógio. A gente não tem para onde ir $[\ldots]$

Não acho! Retrucou Silviano. Em Paris é a mesma coisa.

Em Paris? perguntou Florêncio. Não sabia que você andou por Paris... É boa!

ó parvo, quero dizer que o problema é puramente interior, entende? Não está fora de nós, no espaço!' (ANJOS, 1979 apud ANDRADE, 1996, p. 115).

Ademais, na condição de estrangeiro à cidade e de exclusão dos estratos mais altos, dado o elitismo da capital, a vivência em Belo-Horizonte foi marcada como perda de privilégios, de estabilidade e como falta de integração e, o relativo anonimato, como solidão e exclusão (ANDRADE, 1996). "[...]
Como desejei penetrar nos domínios dessas criaturas! As casas tocavam-se de mistério, e a grade dos jardins parecia demarcar as fronteiras de um mundo diferente do meu, regido por outras leis, submetido a outro sistema planetário" (ANJOS, 1979 apud ANDRADE, 1996, p. 124). Em síntese, para Cyro dos Anjos Belo-Horizonte era uma cidade hostil, fechada, cerimoniosa e excludente. Sentia-se excluído dos Clubes mais finos, das rodas mais intelectualizadas e do grupo de acadêmicos: "Todos os da casa cursavam medicina, e esses estudantes, como os de engenharia, olhavam com desconfiança e desprezo aos que seguiam a carreira jurídica: não era ocupação séria; só parola, intrujice, parasitismo". (ANJOS, 1979 apud ANDRADE, 1996, p. 119). Quanto à artificialidade de Belo-Horizonte, Cyro dos Anjos atribui à sua população, vinda de vários lugares do estado e à falta de passado da cidade; entretanto, para ele, isso não lhe confere um caráter negativo (ANDRADE, 1996).

Nesse sentido, conclui-se que, como bem aponta Andrade (1996), as principais ambivalências expressadas por Drummond e Cyro, em suas representações da cidade e da vida moderna, vinculam-se, de um lado, à experiência com os valores modernos por indivíduos cuja biografia fora marcada por experiências e valores tradicionais da vida na cidade do interior. Por outro lado, à mistura peculiar operada pelo modernismo brasileiro entre 0 novo e 0 tradicional nacional (ibidem). Os modernistas belohorizontinos não eram entusiastas da modernidade, "ao contrário, olharam-na com certa desconfiança, [...] quando lamentam a perda de certos privilégios e das formas de reconhecimento tradicionais, outras vezes, 
expressando os dilemas da vida moderna [...]" (ibidem, p. 178). Assim, da mesma forma que Baudelaire e Zola contribuíram para a criação do mito de Paris como uma cidade aurática, símbolo da metrópole moderna, paradigma exportável, as narrativas de Drummond e de Cyro dos Anjos também contribuíram para o mito de Belo-Horizonte, como uma cidade afável e humana, como eles mesmos a ressignificaram.

\section{CONCLUSÃO}

Paris, Belo-Horizonte! Em figurações históricas específicas e diferentes e, num jogo de espelhos, no qual a imagem refletida depende do olhar de quem contempla e, como tal, o espelho pode operar de forma a criar imagens coincidentes ou não com 0 original, sem que com isso deixem de ser aceitas (PESAVENTO, 2002), essas cidades, encarnaram a identidade da cidade moderna. Segundo Pesavento (ibidem, p. 158; grifo do autor), "Identidade urbana lida com aquelas dimensões [...] 'da cidade real' e da 'cidade ideal', contrabalançando e trocando sinais entre uma 'cidade do desejo' e uma 'cidade do possível'".

As narrativas literárias, dos escritores aqui elencados, falam da representação da cidade moderna, Paris e Belo-Horizonte, que surgia naquele momento. Por meio de uma linguagem poética, metaforizada, mediada pela vivência, pela paixão e pelo desejo desses escritores / leitores que percorreram suas ruas, pode-se entrever a cultura da modernidade. Cultura esta, que é eminentemente urbana e marcada pelas imagens da constante transformação, fugacidade, artificialidade, inautenticidade, contrastes e fragmentação; enfim, imagens ambivalentes. Mas não se pode olvidar que a cidade é onde as coisas acontecem e, a metrópole, é a forma mais específica de realização da vida moderna.

De Paris, capital do mundo para BeloHorizonte, capital das Minas e das Geraes! Imagens quer da memória, ou quer da história, ou, ainda, da literatura; o que importa é que deixaram de ser pedras para tornarem-se cidades; cidades modernas.

\section{REFERÊNCIAS}

ALMEIDA, M. T. R. Baudelaire O Dandy da Modernidade. [2008]. Disponível em: $<$ http://marcostralmeida.blogspot.com/2008/ 02/baudelaire-o-dandy-damodernidade.html>. Acesso em: 3 set. 2009.

ANDRADE, L. T. de. Representações Ambivalentes da Cidade Moderna: A Belo Horizonte dos Modernistas. 195f. Tese (Doutorado em Ciências Humanas: Sociologia) - Instituto Universitário de Pesquisas do Rio de Janeiro, Rio de Janeiro, 1996.

ARGAN, G. C. O espaço visual da cidade. Espaço \& Debates, São Paulo, n. 33, p. 1826, 1991.

BENJAMIN, W. O Flâneur. In: BENJAMIN, W. Obras Escolhidas III: Charles Baudelaire: um lírico no auge do capitalismo. São Paulo: Brasiliense, 1991. p. 33-65.

BOLLE, W. Cidade e Memória. In: BOLLE, W. Fisiognomia da Metrópole Moderna: Representação da história em Walter Benjamin. São Paulo: Edusp, 2000. p. 31363.

DELGADO, L. de A. N. História Oral: 
memória, tempo, identidades. Belo In: PECHMAN, Robert Moses (Org.). Horizonte: Autêntica, 2006.

DELGADO, L. de A. N. Tempo de reencontro em Fernando Sabino: memória, literatura, história e modernidade. ArtCultura, Uberlândia, v. 9, n. 14, p. 143-55, 2007.

JULIÃO, L. Belo Horizonte: Itinerários da Cidade Moderna (1891-1920). In: DUTRA, Eliane de Freitas (Org.). BH: horizontes históricos. Belo Horizonte: C/Arte, 1996. p. 49-118.

MAGNANI, J. G. C. De perto e de Dentro: notas para uma etnografia urbana. Revista Brasileira de Ciências Sociais, São Paulo, v. 17, n. 49, p. 11-29, jun. 2002.

MATTOS, O. Memória e História em Walter Benjamin. In: CUNHA, M. C. P. (org.). O Direito à Memória: patrimônio histórico e cidadania. São Paulo: Departamento do Patrimônio Histórico/Secretaria Municipal de Cultura, 1992. p. 151-60.

PECHMAN, R. M. Pedra e Discurso: cidade, História e Literatura. Revista Semear, Rio de Olhares sobre a Cidade. Rio de Janeiro: UFRJ, 1994. p. 3-8.

PESAVENTO, S. J. O Imaginário da Cidade: visões literárias do urbano: Paris, Rio de Janeiro, Porto Alegre. 2. ed. Porto Alegre: UFRGS, 2002.

SCHORSKE, C. E. A cidade segundo o pensamento europeu - de Voltaire a Spengler. Tradução de Hélio Slan Saltorelli. Espaço \& Debates, São Paulo, n. 27, p. 4757, 1989.

SENRA, M. C. S. M. de L. Sob o Signo da Imagem: A Contribuição do Patrimônio Cultural Edificado na Construção Identitária da Cidade de Varginha. 2002. $182 f$. Dissertação (Mestrado em Ciências Sociais) - Programa de Pós-Graduação em Ciências Sociais, Pontifícia Universidade Católica de Minas Gerais, Belo Horizonte, 2002.

ZOLA, É. Germinal. Tradução de Francisco Bittencourt. São Paulo: Abril Cultural, 1979. p. 3.

<htpp://www.letras.pucrio.br/catedra/revista/3Sem_06.html>.

Acesso em: 30 ago. 2009.

PECHMAN, R. M. Olhares sobre a Cidade. 